\title{
THE EFFECT ON LIVER STRUCTURE OF TREAT- MENT WITH ADRENOCORTICOTROPIN UNDER VARIED DIETARY CONDITIONS
}

\author{
BURTON L. BAKER, DWIGHT J. INGLE, CHOH H. LI AND \\ HERBERT M. EVANS \\ Department of Anatomy, University of Michigan Medical School, Ann Arbor; \\ Research Laboratories, The Upjohn Company, Kalamazoo, Michigan and \\ Institute of Experimental Biology, University of California, \\ Berkeley
}

TWENTTY-FOUR FIGURES

The manner in which the physiology and anatomy of the liver are regulated or modified by endocrine secretions is poorly understood. Further, in view of the broad extent of anterior hypophyseal control over the various structures of the body, it is reasonable to expect that an organ of such varied and diverse functions as the liver might be affected more significantly by hypophyseal activity than is apparent at the moment. The recent isolation of hypophyseal adrenocorticotropin in an apparently homogeneous form (Li, Simpson and Evans, '42) provides a useful tool for study of the relationship of the anterior hypophysis to the cytology of the liver. One might presume that through a stimulation of adrenal cortical secretion, the physiology, and hence the morphology, of the liver would be altered since it has been established that some of the steroids which have been isolated from the adrenal cortex modify certain metabolic activities of the liver. For example, they have been reported to influence carbohydrate metabolism and to increase the level of liver glycogen. These steroids promote the conversion of protein (Long, Katzin and Fry, '40), pyruvate and d-lactate (Koepf et al., '41) to carbohydrate and the conversion of glucose 
to glycogen (Britton and Corey, '41); they inhibit the rate of glycogenolysis (Seckel, '40) and possibly affect hepatic carbohydrate indirectly by inhibiting the peripheral utilization of carbohydrate (Ingle and Thorn, '41). From the above statement it is evident that protein metabolism is affected in the liver, at least insofar as the cortical steroids stimulate the catabolism of protein to form carbohydrate. The relationship of the cortical steroids to the physiology of fats in the liver is less clearly understood. A correlative review by Ingle ('43) of the available information pertaining to this problem indicates quite definitely that such a relationship does exist although its exact nature is obscure at the present time.

Therefore, we have carried out a microscopic study of liver cells following the administration of adrenocorticotropin in the hope that in the light of the known action of cortical steroids on the liver, information might be obtained which would further our understanding of some aspects of liver cytology. Since variations in diet alone may cause changes in liver structure, the action of adrenocorticotropin was studied in rats fed high fat, high carbohydrate or high protein diets. Special attention was given to fatty substances and since a fatty infiltration of the liver was induced in some of the animals, the basophilia, alkaline phosphatase and acid phosphatase were studied also in order to secure some information concerning the functional status of the fat-laden cells. The scarcity of this hormone preparation and the fact that in some cases we have used rather large doses for periods up to 21 days are additional reasons why we are reporting our results in some detail.

Such a study assumes added significance in the light of the recent postulation by Selye ('46) that prolonged subjection of the body to stress may be an etiological factor in certain diseases, the general physiological and anatomical changes induced by stress being termed the "general adaptation syndrome." Considerable evidence shows that many of the structural changes characteristic of the "general adaptation 
syndrome" are elicited through the action of adrenal cortical secretions. An increased production of these substances is brought about, in turn, through stimulation of the hypophysis by conditions of stress to release greater amounts of adrenocorticotropin. Thus, it appeared possible that a study of the effects of the administration of adrenocorticotropin on the liver might help to clarify the manner in which the liver reacts under circumstances of stress.

TABLE 1

Composition of fluid diets $(\mathrm{gm})$.

\begin{tabular}{|c|c|c|c|}
\hline CONSTITUENT & $\begin{array}{c}\text { HIGH } \\
\text { CARBO- } \\
\text { HYDRATR }\end{array}$ & $\begin{array}{l}\text { HIGH } \\
\text { FAT }\end{array}$ & $\begin{array}{c}\text { HIGH } \\
\text { PROTEIX }\end{array}$ \\
\hline Cellu flour (Chicago Dietetic Supply) $\therefore \ldots \ldots$ & 120 & 120 & 60 \\
\hline Osborne and Mendel salt mixture .... & 40 & 40 & 20 \\
\hline Wheat germ oil $\ldots \ldots \ldots \ldots \ldots \ldots \ldots$ & 10 & 1.0 & 5 \\
\hline Mazola oil plus $100 \mathrm{mg}$ vitamin $\mathrm{K}$ & 10 & 10 & 10 \\
\hline Cod liver oil $\ldots \ldots \ldots \ldots \ldots \ldots \ldots \ldots \ldots$ & 10 & 10 & 5 \\
\hline Dried yeast (Pabst) $\ldots \ldots \ldots \ldots \ldots \ldots \ldots$ & 100 & 100 & 50 \\
\hline Starch (soluble, Difco) & 330 & & \\
\hline 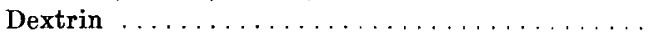 & 335 & & \\
\hline$\ldots \ldots \ldots \ldots \ldots \ldots \ldots \ldots \ldots \ldots$ & 335 & & \\
\hline Egg albumin (Merck) $\ldots \ldots \ldots \ldots \ldots \ldots \ldots$ & 160 & 160 & 200 \\
\hline Lactalbumin $\ldots \ldots \ldots \ldots \ldots \ldots \ldots \ldots \ldots$ & & & 200 \\
\hline Casein $\ldots \ldots \ldots \ldots \ldots \ldots \ldots \ldots \ldots \ldots \ldots$ & & & 50 \\
\hline Mazola oil $\ldots \ldots \ldots \ldots \ldots \ldots \ldots \ldots \ldots \ldots \ldots$ & & 200 & 65 \\
\hline Butter fat $\ldots \ldots \ldots \ldots \ldots \ldots \ldots \ldots \ldots \ldots \ldots \ldots \ldots \ldots \ldots$ & & 260 & \\
\hline Water to make total volume of $\ldots \ldots$ & $2000 \mathrm{~cm}^{3}$ & $2000 \mathrm{~cm}^{3}$ & $1500 \mathrm{~cm}^{3}$ \\
\hline
\end{tabular}

\section{MATERIALS AND METHODS}

Male rats from an infection-free colony of the SpragueDawley strain were maintained on a diet of Purina Dog Chow until they reached a weight of $300 \pm 5 \mathrm{gm}$. They were then maintained on a fluid diet administered by stomach tube each morning (8:30 to $9: 15$ A.M.) and afternoon (4:15 to $5: 00$ P.M). The technique of forced-feeding and the diets used were modifications of those described by Reinecke, Ball and Samuels ('39). The diets were made according to table 1. During the period of adaptation to forced-feeding the amount of diet 
was increased gradually to prevent the development of "food-shock." The animals were brought to a full feeding on the fifth day. Amounts of $26 \mathrm{~cm}^{3}$ per day of the high carbohydrate and of the high fat diets and $40 \mathrm{~cm}^{3}$ per day of the high protein diet were given. These volumes of diet were estimated to be isocaloric and contained the same basal constituents. The animals were housed in an air-conditioned room at a temperature of 74 to $78^{\circ} \mathrm{F}$. and with the humidity at $30-35 \%$ of saturation.

The adrenocorticotropin was prepared by the procedure of Li, Evans and Simpson ('43). Following control periods of 14 days the experimental animals were given adrenocorticotropin by subcutaneous injection in divided doses every 2 hours for a total of 8 injections per day. The control animals were given injections of $0.9 \%$ sodium chloride solution at the same times.

In experiment 1, 2 rats on each of the 3 diets $^{1}$ were injected with $1 \mathrm{mg}$ of adrenocorticotropin per day for 21 days. An equal number of control animals were studied. Experiment 2 was identical to experiment 1 except that the dosage of adrenocorticotropin was $3 \mathrm{mg}$ per day. In experiment $3,8 \mathrm{mg}$ of adrenocorticotropin per day were injected for 10 days. The other details remained the same as in experiments 1 and 2 except that 4 rats, instead of 2, were maintained on the high carbohydrate diet. At the end of the injection periods all of the animals were anesthetized with ether and exsanguinated for necropsy which followed immediately. The animals remained in good health throughout all phases of the experiment except for inhibition of growth and weight loss caused by the adrenocorticotropin. The body weights of the rats at the beginning and end of the experiments are summarized in table 2.

The data on the urinary constituents of these animals are reported elsewhere by Ingle, Prestrud, Li and Evans (unpublished).

${ }^{2}$ For the sake of brevity, rats fed high carbohydrate, high fat or high protein diets will be designated simply as "carbohydrate," "fat," or "protein" animals. 
For observation of changes in general histology, a piece of the median lobe of the liver, measuring about $1 \mathrm{~cm} \times 7 \mathrm{~mm}$ $\times 5 \mathrm{~mm}$, from each rat was fixed in Bouin's fluid, sectioned in paraffin and stained with Harris' hematoxylin and eosin. Basophilia was demonstrated by fixation of somewhat smaller blocks from the same lobe in Zenker-acetic followed by staining with methylene blue and eosin. Although Bouin's fluid is not as satisfactory a fixing fluid for the study of basophilia,

TABLE 2

Effect of adrenocorticotropin on body weight of force-fed rats (average in $g m$ ).

\begin{tabular}{|c|c|c|c|c|c|c|c|c|}
\hline \multirow{2}{*}{\multicolumn{2}{|c|}{$\begin{array}{l}\text { ADREN. } \\
\text { MG/DAY }\end{array}$}} & \multirow{3}{*}{$\begin{array}{c}\underset{\text { DAYS }}{\text { TEEATED }} \\
21\end{array}$} & \multicolumn{2}{|c|}{ CARBOHYDRATY } & \multicolumn{2}{|c|}{ FAT } & \multicolumn{2}{|c|}{ PROTHIN } \\
\hline & & & \multirow{2}{*}{$\begin{array}{l}\text { Start } \\
307\end{array}$} & \multirow{2}{*}{$\frac{f \text { Finish }}{297}$} & \multirow{2}{*}{$\begin{array}{r}\text { Start } \\
319\end{array}$} & \multirow{2}{*}{$\begin{array}{c}\text { Finish } \\
302\end{array}$} & \multirow{2}{*}{$\begin{array}{l}\text { Start } \\
315\end{array}$} & \multirow{2}{*}{$\begin{array}{c}\text { Finish } \\
339\end{array}$} \\
\hline 1 & $\mathbf{A F}$ & & & & & & & \\
\hline & FC & & 311 & 347 & 311 & 355 & 312 & 366 \\
\hline \multirow[t]{2}{*}{3} & $\mathbf{A F}$ & 21 & 314 & 286 & 315 & 282 & 312 & 304 \\
\hline & $\mathrm{FC}$ & & 311 & 342 & 314 & 352 & 317 & 362 \\
\hline \multirow[t]{2}{*}{8} & $\mathbf{A F}$ & 10 & 312 & 287 & 306 & 281 & 316 & 300 \\
\hline & FC & & 307 & 316 & 313 & 327 & 317 & 329 \\
\hline
\end{tabular}

$\mathbf{A F}=$ adrenocorticotropin-treated, force-fed rats.

$\mathrm{FC}=$ force-fed controls.

sections of material preserved in this fixative also were stained with methylene blue and eosin. The variations in basophilia induced by the experimental procedures in these preparations were compared with and used as a control for those observed following Zenker-acetic fixation. These procedures were employed on liver tissue from all rats.

In order to ascertain the extent to which ribonucleic acid accounted for the basophilia of the liver, sections were incubated for $2 \frac{1}{4}$ hours at $55^{\circ} \mathrm{C}$. in a $0.1 \%$ solution of crystalline ribonuclease ${ }^{2}$ dissolved in McIlvaine's disodium phosphatecitric acid buffer at $\mathrm{pH}$ 6.9. The hydrogen ion concentration was determined with a glass electrode $\mathrm{pH}$ meter and control

\footnotetext{
${ }^{3}$ We wish to express our gratitude to Dr. Moses Kunitz, The Rockefeller Institute for Medical Research, for supplying us with crystalline ribonuclease.
} 
sections were treated with the buffer solutions under identical conditions.

Additional techniques were used in studying the livers of rats in experiment 3 , the treated animals of which received 8 $\mathrm{mg}$ of adrenocorticotropin per day for 10 days. Portions of the median lobe of the liver were fixed in $10 \%$ neutral formalin for the study of fats, these pieces being imbedded in gelatin (Zwemer, '33), sectioned at $15 \mu$ on a freezing microtome, stained with Sudan III or IV (Herxheimer's solution, Cowdry, '43) and mounted in glychrogel (Zwemer, '33). Some sections were stained with Nile blue sulphate in order to demonstrate non-saturated glycerides. Other sections were place in $2.5 \%$ ferric ammonium sulphate $\left(37^{\circ} \mathrm{C}\right.$.) for 3 days and then treated with strong sulphuric acid (Schultz, '24) in an attempt to reveal cholesterol and its esters. The procedures of Gomori were used for the study of alkaline ('39) and acid glycerophosphatase ('41a) after fixation in $95 \%$ alcohol and cold acetone, respectively. The incubation for alkaline phosphatase was carried out for 4 and 23 hours in a sodium barbital buffer at $\mathrm{pH} 9.4$ and for acid phosphatase the sections were incubated 15 and 22 hours in acetate buffer at $\mathrm{pH}$ 5.0.

\section{OBSERVATIONS}

In the subsequent description of changes induced in the liver by variation of the diet, the injection of adrenocorticotropin, or by a combination of both treatments, observations reported as being characteristic of a lobule may be applied to the majority of the lobules of any given section unless a statement is made to the contrary. Likewise, these observations may be understood to apply to numerous sections taken from various regions of the blocks of liver which were excised as previously described.

Fatty substances. Fats were studied in the livers of rats which received $8 \mathrm{mg}$ of adrenocorticotropin daily for 10 days. As was to be expected, diet alone exerted considerable influence on the quantity of sudanophilic materials to be found 
in the liver. Many observers have noted that the livers of rats fed the usual stock laboratory diets contained very little histologically demonstrable fat. This situation obtained in the control rats on both the carbohydrate and protein diets (figs. 7 and 11). In one of the carbohydrate controls we found no fat and in the other, a few small droplets in occasional cells located in the peripheral zone of some lobules. The protein controls were more variable, in one, a few cells contained sparse minute droplets while in the other, many minute to medium-sized droplets were found scattered irregularly throughout the lobule but were most prominent in the middle and outer zones. On the fat diet significant amounts of fat were to be found throughout the lobule but here also the inner zone frequently showed less than the other portions of the lobule (fig. 9).

Following treatment with adrenocorticotropin, the most striking and consistent change observed in the fat content was a considerable increase in the quantity of this substance in the livers of rats fed the carbohydrate diet (fig. 8). The droplets varied from a minute to moderate size (about onefifth that of the nucleus) and were distributed rather uniformly throughout the cell (fig. 24). This effect occurred in all of the 4 experimentals as compared with the 2 controls and was characteristic of all lobules in a section. In contrast, no such marked increase was evident in the protein-fed animals (fig. 12), in one adrenocorticotropin-treated rat a slight increase being observed in some lobules and in the other rat, a reduction. It was felt that the increase in the one rat was probably not significant and it did not compare at all with the magnitude of the response in the carbohydrate-fed rats. As previously pointed out, the livers of the controls maintained on a high fat diet contained considerable quantities of sudanophilic fat. Concurrent treatment with adrenocorticotropin did not lead to a significant increase (fig. 10), in one rat there being a suggestion of such a change but in the other, a definite reduction. In order to show that the material being stained by Sudan IV was fat, sections from these specimens 
were treated with acetone for 48 hours and then stained. In all cases, the affinity of the tissue for the stain was lost completely.

Additional techniques were employed in order to determine the type of fat being deposited in the liver under the influence of adrenocorticotropin. In the opinion of Lison ('36) fats to which Nile blue sulphate gives a rose color are non-saturated glycerides. Application of this technique to formalinfixed sections, brought out material which stained with a rose color. The quantity of this substance in the various specimens and its distribution within the liver lobule corresponded rather well with the fat which stained with Sudan. This suggested that the major portion of the sudanophilic fat consisted of non-saturated glycerides.

The Schultz reaction also was employed in the analysis of these specimens. This test indicates unsaturation of the sterol molecule although it cannot be considered a specific test for sterols since other unsaturated polynuclear hydromatic compounds behave similarly (Fieser, '36). The test was repeated 3 times but the fat droplets which stained with Sudan and Nile blue sulphate failed to develop a blue-green color and in no case did a distinctive color develop in the general cytoplasm. This technique was controlled by running parallel tests on other tissues which regularly gave a deep blue-green reaction.

Vacuolation. Since formalin-fixed samples of the liver for use in the study of fat were not available from rats treated with the lower doses of adrenocorticotropin, observation of the extent of vacuolation in the liver cells fixed by other methods is helpful in estimating the amount of fatty infiltration since the vacuolation is partially dependent on the amount of fat which has been dissolved out of the cells.

Variation in diet alone modified considerably the quantity and character of the vacuoles. Carbohydrate feeding resulted in the appearance of sparse vacuoles throughout the lobule most of which were so minute as to be hardly visible at a magnification of 430 . These were due probably to the deposition 
of glycogen. Likewise, on the high protein diet, vacuolation was slight (fig. 5) in some specimens small vacuoles being observed chiefly in the periphery of the hepatic cells. Generally, the density of the cytoplasm was quite similar in all zones of the lobule. The livers from rats fed a fat diet were profusely vacuolated (fig. 3 ), practically all cells being affected to a variable degree. Towards the periphery of the lobule, the vacuoles tended to be small while in the inner zone not only were the vacuoles more numerous but some were large equalling or surpassing the nucleus in size.

Adrenocorticotropin exerted a marked effect on the vacuolation in animals maintained on the carbohydrate diet. In contrast to the control as described above, $1 \mathrm{mg}$ daily for 21 days greatly increased the amount of vacuolation throughout the lobule. Some cells, especially in the peripheral zone, showed considerably more vacuolation than neighboring ones. The vacuoles in this region of the lobule were distinguished by a remarkable uniformity in size and even distribution throughout the cytoplasm of the cells so affected. They were generally about one-fifth the diameter of the nucleus. Other cells in the inner and middle zones of the lobules were greatly enlarged and practically clear with very little remaining cytoplasm. Increasing the dosage of hormone to $3 \mathrm{mg}$ per day for 21 days did not intensify this structural change. However, increasing the dosage to $8 \mathrm{mg}$ daily for a 10-day period did further increase the vacuolation, practically all cells throughout the sections studied showing this modification (figs. 1 and 2). The similarity in size, quantity and distribution of these vacuoles to the histologically demonstrated fat droplets, showed that this vacuolation resulted chiefly from the removal of fat rather than glycogen from the hepatic cells. In a few cases at low and high doses, infrequent small areas were observed in which the hepatic cells were transformed into a large signet-ring form with a peripheral nucleus and these resembled a fat cell in every respect (fig. 18). Very few nuclei showed any evidence of degeneration. 
Treatment of rats on a high protein diet with adrenocorticotropin gave less decisive results. Doses ranging from 1 to 3 $\mathrm{mg}$ daily for 21 days seemed to increase the vacuolation slightly, this vacuolation being confined to the inner zone of the lobule where vacuoles of varied sizes appeared, a few of them being as large as the nuclei of the hepatic epithelial cells. Increasing the dosage over this range was without effect. But in none of the rats in which the higher dose of $8 \mathrm{mg}$ was injected for 10 days was there a definite increase in vacuolation over that in the controls (fig. 6).

In regard to the effect of adrenocorticotropin on vacuolation in the rats fed fat diets, a definite conclusion is difficult because the control specimens were themselves quite extensively vacuolated. In general, at all dose levels, the vacuolation seemed to be increased to a variable degree by adrenocorticotropin (fig. 4). In most instances this change was slight.

Basophilia. As has been noted by many observers, cytoplasmic basophilia in the liver is modified considerably by the type of diet, and the form of the basophilic structures varies in the different zones of the lobule and with the type of fixative used to demonstrate it. It appeared most prominently in the control animals on the carbohydrate diet. Following fixation in Zenker-acetic, the basophilia of the outer zone was usually in the form of irregular threads joined into indistinct networks (fig. 19). Less distinct finer particles appeared in various parts of the cytoplasm. The basophilia tended to be most concentrated near the nucleus. In contrast, in the inner zone the basophilia was aggregated into dense clumps which were quite numerous (fig. 20). The form of the basophilic material in the middle zone was intermediate between these 2 extremes but generally resembled more that of the outer zone. Digestion with ribonuclease completely destroyed the cytoplasmic affinity for methylene blue, showing that this basophilia was due to the presence of ribonucleic acid.

The hepatic cells of the fat-fed controls contained less basophilic material (fig. 23) which in some cases was dis- 
tributed in a somewhat different manner due apparently to the presence of the fat droplets. Most of it consisted of fine fibrillae or small clumps compressed between the vacuoles or against the cell membrane. This arrangement characterized especially the Bouin-fixed preparations which had been stained with eosin and methylene blue.

Our preparations did not make possible a definite conclusion in regard to the effect of a protein diet on the basophilia. In some it was more prominent than that in the animals on a carbohydrate regimen and in others, less prominent. Generally, it was more conspicuous than in the fat-fed controls.

The only clear-cut effect revealed by our preparations on the basophilia following treatment with adrenocorticotropin occurred on the carbohydrate diet in which case it was reduced (fig. 21). The effect varied in different cells, appearing to be related directly to the extent of the vacuolation. The most marked general reduction occurred in those rats in which the majority of liver cells were heavily vacuolated.

Alkaline glycerophosphatase. Gomori ('41b) has reported the liver of the rat to give a practically negative reaction for alkaline glycerophosphatase except for the adventitia of branches of the hepatic artery, although Wachstein ('45) found some activity. These results are in substantial agreement with those of other workers who have analyzed the liver biochemically and our observations confirm Gomori's findings for the epithelial cells of the rat liver. In our specimens the amount of darkening of the cytoplasm was uniformly slight and that which did occur was chiefly peripherally located in the lobule, where the nuclei also stained faintly. The sinusoidal walls were practically negative. Neither diet nor treatment with adrenocorticotropin made a significant difference in this outcome (figs. 16 and 17).

The adequacy of the technique was demonstrated by two means. First, control sections of other tissues which contain large amounts of alkaline glycerophosphatase were run through with the liver slides. Secondly, in all slides certain structures associated with the portal canal showed an in- 
tensely positive reaction to the Gomori procedure. Even in counter-stained preparations it was not always possible to ascertain the identity of these structures because of the large amount of black cobalt sulfide deposited within them. However, in many instances they were seen to be definitely tubular in form and appeared to be blood capillaries adjacent to the interlobular bile ducts.

Acid glycerophosphatase. It has been demonstrated by Bodian and Mellors ('45) that with the disappearance of Nissl substance (nucleoprotein) in neurons following injury to the axon, there occurs a marked increase in the amount of acid phosphatase in the cell during the period of repair. Thus, the reciprocal relationship of ribonucleic acid and phosphatase in this instance suggested that the phosphatase might play an important part in the manufacture of new protein either directly, or indirectly through aiding in the re-constitution of ribonucleic acid. Since we have demonstrated a reduction in basophilia (ribonucleic acid) in the livers of rats on the fat diet, or on the carbohydrate diet plus treatment with adrenocorticotropin, we wished to see whether or not these cells also would exhibit an increase in their acid phosphatase activity, such a finding possibly suggesting an attempt on the part of the cells to recover from a depressed metabolic state.

Acid phosphatase preparations were available from the rats of only 1 experimental group and because of the small number of cases no final conclusions may be drawn. Further, as has been observed by others, the reaction is quite variable in various parts of a section of liver. The procedure was repeated 3 times on the livers of these 8 rats. It appears fairly certain after comparing specimens from the 3 carbohydratefed rats treated with adrenocorticotropin with those of the control, that no significant increase in acid phosphatase accompanied the fatty infiltration (figs. 13 and 14). In fact, there was evidence of some reduction. There also seemed to be somewhat less acid phosphatase in the fat-fed control than in the carbohydrate control. However, in many areas the change was so slight (fig. 15) that, in view of the variability 
of the staining reaction, these differences could not be considered of much significance. Wachstein ('45) reported an apparent reduction in both alkaline and acid phosphatase ac. tivity in livers of rats maintained on a choline-free, protein deficient diet. Many of the hepatic cells of his rats, however, were more extensively distended with fat than was true of our rats.

\section{DISCUSSION}

Fats. The occurrence of fatty infiltration of the liver in animals treated with hypophyseal extracts is not without precedent. This with ketonuria constituted the outstanding effects observed during treatment of animals with the socalled "ketogenic" extract as reported by Best and Campbell ('36, '38). This preparation was comparatively crude and our results are of interest in that they relate the induction of at least 1 form of fatty infiltration of the liver by treatment with hypophyseal extracts to one of the recognized principles produced by the anterior hypophysis. According to Li, Evans and Simpson ('43) the adrenocorticotropic extract employed in these experiments is free of growth hormone and contains less than $0.10 \%$ of follicle-stimulating, interstitial cell-stimulating and thyrotropic factors, thus implicating rather definitely the adrenal cortex-stimulating hormone as the causative agent.

Also, previous work has demonstrated the essential rôle of the adrenal cortex in this phenomenon since MacKay and Barnes ('37) and Fry ('37) found adrenalectomy to prevent the development of fatty livers following administration of anterior hypophyseal extract. Adrenalectomy was found also to inhibit the deposition of liver fat pursuant to phosphorus poisoning (Verzár and Laszt, '36), partial hepatectomy (MacKay and Carne, '38), feeding of high fat diets, alkalosis brought about by feeding sodium bicarbonate or following injections of epinephrin (MacKay, '37), and total pancreatectomy (Long, Lukens and Fry, '36). Nevertheless, it should be emphasized that the appearance of fatty livers has not been 
reported following over-dosage with adrenal cortical extracts or pure cortical steroids. The cytology of the liver and its fat content have not been the subjects of close attention in these studies.

On the basis of present knowledge, there would appear to be 2 possible explanations for the accumulation of fat in the liver in our experiments: first, an interference with the normal rate of transfer of fat to or away from the liver and, second, alteration of the internal metabolism of the liver especially as it relates to carbohydrates. Impairment of the normal functioning of a lipotropic factor might modify the capacity of the body to transport fat. One of these factors, choline, has been shown to contribute to the formation of a phospholipid of the lecithin type which appears to be important in the transport of fat. Certain findings which have been reported in connection with studies of lipotropic factors are pertinent to our experiments in which the greatest deposition of liver fat was observed in rats on a high carbohydrate diet and which fat seemed to be of a glyceride type. Best and Huntsman ('35) found that a high content of dietary carbohydrate facilitated the deposition of liver fat in rats deprived of choline. Further, numerous publications (for review see McHenry and Patterson, '44), showed that the primary action of choline is on the glyceride fraction. In view of this suggestive evidence, it is pertinent to note that previous attempts have been made to prevent the accumulation of fat in the liver following treatment with pituitary extracts by feeding lipotropic factors such as choline. At first, such attempts in the rat (MacKay and Barnes, '38) and rabbit (Mukerji and Guha, '38) met with failure. However, Julian et al. ('42) successfully prevented the accumulation of liver fat by feeding pancreatic extract (containing the lipotropic factor, lipocaic) and criticized MacKay and Barnes for having used too small a dose. Verzár and Laszt ('36) suggested that the adrenal cortex controls the transport of fat and later Barnes et al. ('41) produced confirmatory evidence showing further that adrenalectomy impaired the entrance of fed 
tagged fatty acids into the neutral fat of the liver but not into the phospholipids. This defect was alleviated by the administration of cortical extract.

In our study, the most marked increase in the deposition of liver fat occurred in those rats fed a high carbohydrate diet which suggests that this augmentation might be related to a modification in the capacity of the liver to metabolize carbohydrate, this substance being converted to and deposited as fat. The relationship of certain of the cortical steroids to carbohydrate metabolism has been pointed out previously. In addition Ingle et al. ('45) have shown administration of 17-hydroxycorticosterone and 17 hydroxy-11-dehydrocorticosterone to cause hyperglycemia and glycosuria. These changes were duplicated by adrenocorticotropin (Ingle, Li and Evans, '46) showing that the preparation employed by us does have an effect on carbohydrate metabolism which undoubtedly is mediated by the adrenal cortex.

In seeking an explanation for the fatty infiltration of the liver induced by hypophyseal extracts it should be noted that most of the experiments of Best and collaborators were performed on fasted animals, and in this situation they concluded that the liver fat was derived from the body depots (Barrett et al., '38). They pointed out further that when animals were fed a low protein-high carbohydrate lipotropic diet, the fat which accumulated in the liver was not derived from the body depots but probably was converted from ingested carbohydrate. MacKay ('37) also concluded that the adrenal more likely affected liver fat indirectly through carbohydrate metabolism than by altering the transport mechanism of fat. The fact that in our experiments the most striking effect was observed on a high carbohydrate diet suggests a similar conclusion. Yet a similarity to the fatty infiltration obtained with diets lacking in lipotropic factors is apparent since in both cases the glyceride fraction appears to be affected the most.

To what extent may the hypophyseal-adrenal regulation of fatty infiltration of the liver be involved in the pathogenesis 
of disease in this organ? It has been shown experimentally in dogs that fatty infiltration of the liver precedes the development of fibrous tissue (Chaikoff et al., '38, '43) and a similar sequence of changes has been suggested in the development of cirrhosis of the liver in diabetes and chronic alcoholism (Connor, '38). Likewise, it has been demonstrated that a wide variety of noxious agents such as X-rays, cold, colchicine (Leblond, Thoai and Segal, '39) and excessive muscular exercise (Selye, '39) will cause fatty infiltration of the liver, thus making this change characteristic of the general adaptation syndrome. However, actual cirrhosis has not been reported after such treatment and at present one could only speculate on whether prolonged treatment with adrenocorticotropin or subjection to stress eventually could induce cirrhotic changes. In our specimens, it seemed that although many of the liver cells contained a great deal of fat, still they were not damaged severely. The loading of cells with fat to the extent that they assumed the signet ring appearance of connective tissue fat cells occurred in only localized foci. Nuclear pycnosis was not observed and only occasional indications of karyolysis were seen. One could not escape the impression that with cessation of the adrenocorticotropin treatment, the fat composition of the liver would have returned to normal rapidly.

In this connection it is important to note that Selye ('46) has found diets high in protein to greatly facilitate the production of experimental "diseases of adaptation" induced by desoxycorticosterone or anterior pituitary extract while diets high in carbohydrate are protective. Thus, if the fatty infiltration of the liver observed in our experiments were to be regarded as an early change in the development of a diseased liver, then the effect of diet was the reverse of that reported by Selye, since its induction was facilitated by the high carbohydrate diet and it was minimal on the diet high in protein.

In spite of the considerable amount of evidence which has been presented indicating that the hypophysis-adrenal complex may be involved in the appearance of fatty infiltration of the liver, still the integrity of these glands cannot be re- 
garded as essential to such a change since fatty livers have appeared in hypophysectomized-thyroidectomized dogs (Chaikoff et al., '43).

Basophilia and phosphatases. Techniques for the study of the variations in basophilia and phosphatases are of value in this investigation since they may reveal evidence concerning the physiological state of the liver under the influence of adrenocorticotropin. It was thought originally that the basophilic substance of the hepatic cells represented stored protein (Berg, '12 ; Pfuhl, '32). Subsequent studies have demonstrated that these structures contain a high percentage of ribonucleic acid, upon the presence of which is dependent their basophilic staining reaction. Studies of the ultraviolet absorption spectrum of Nissl substance in nerve cells by Gersh and Bodian ('43) showed it to be identical to that of the nucleoproteins. Rather definite proof of this fact has been furnished by the destruction of the basophilia of the liver cytoplasm by digestion with ribonuclease by Brachet ('40), Davidson and Waymouth ('44), Biesele ('44), Deane ('46) and confirmed by us in this study. The cytoplasmic nucleoprotein may be an important indicator of certain physiological activities since much evidence has accumulated to indicate that it plays a rôle in growth (Caspersson and Schultz, '39) and in protein synthesis in general (Greenstein, '44). The rather extensive evidence relating basophilia to protein synthesis in lymphocytes, blood granulocytes, serozymogenic cells, human placenta and neurons has been reviewed elsewhere (Dempsey and Wislocki, '46). If the hepatic nucleoproteins bear such a relationship to the formation of new protein, then the reduction in nucleoprotein observed in the fatty livers of animals on high carbohydrate diets and adrenocorticotropin treatment, might be expected to influence the capacity of the liver to produce fibrinogen, serum albumen and some globulins, these proteins appearing to be wholly or partly synthesized by this organ (Madden and Whipple, '40). Years ago it was suggested by Berg that variations in size and number of the basophilic (pyroninophilic) bodies are indi- 
cative of disturbed protein metabolism. However, the changes in the phosphatases observed in our experiments were too slight to be interpreted as indicative of such a disturbance in the normal function of the liver, although they have been linked repeatedly with the metabolism of the nucleoproteins because of their phosphorylating activity.

\section{SUMMARY}

Liver structure was studied in adult rats maintained on high carbohydrate, high fat or high protein diets and treated with purified adrenocorticotropic extract. In the livers of the rats fed the high carbohydrate diet and treated with the hormone, changes occurred which suggested some alteration in functional capacity. Chief of these effects was a fatty infiltration, this fat appearing on the basis of various cytochemical tests, to be of a glyceride type. There was no significant evidence of degeneration. Vacuolation of the hepatic cells as observed in the usual histological preparations reflected these fatty deposits. Concurrently with this change, the cytoplasmic ribonucleoprotein was reduced. No increase occurred in acid glycerophosphatase activity and no change in alkaline glycerophosphatase. On the basis of this study, it is believed that in the rats treated with adrenocorticotropin and fed high carbohydrate, sufficient fat accumulated in the liver so that some of its functions might have been impaired.

\section{LITERATURE CITED}

Barnes, R. H., E. S. Muliber and G. O. BurR 1941 The influence of the adrenals on the transport of fat into the liver. J. Biol. Chem., 140: 247-253.

Barrett, H. M., C. H. Best and J. H. Ridout 1938 A study of the source of liver fat using deuterium as an indicator. J. Physiol., 93: 367-381.

BERG, W. 1912 Über spezifische in der Leberzellen nach Eiweissfutterung auftretende Gebilde. Anat. Anz., 42: 251-262.

Bess, C. H., AND J. CAMPBeil 1936 Anterior pituitary extracts and liver fat. J. Physiol., 86: 190-203.

1938 The effect of anterior pituitary extracts on the liver fat of various animals. J. Physiol., 92: 91-110.

Best, C. H., AND M. E. Hun'ssmax 1935 The effect of choline on the liver fat of rats in various states of nutrition. J. Physiol., 89: 255-274. 
BIEshe, J. J. 1944 Chromosome size in normal rat organs in relation to $B$ vitamins, ribonucleic acid, and nuelear volume. Cancer Res., 4: 529-539.

Bodian, D., AND R. C. MFLlors 1945 The regenerative eycle of motoneurons, with special reference to phosphatase activity. J. Exp. Med., 81: $469-488$.

BrAchET, J. 1940 La détection histochimique des acides pentosenueléiques. Comp. rend. Soc. de Biol., 133: 88-90.

Britron, S. W., AND E. L. COREY 1941 Pancreatic and corticoadrenal involvement in carbohydrate regulation. Am. J. Physiol., 131: 790-798.

Caspersson, T., and J. Schultz 1939 Pentose nueleotides in the eytoplasm of growing tissues. Nature, 143: 602-603.

Chaikoff, I. I., C. L. Connor AND G. R. BIskind 1938 Futty infiltration and eirrhosis of the liver in depanereatized dogs maintained with insulin. Am. J. Path., 14: 101-110.

Chatrofw, I. I., K. B. Eichorn, C. I. Connor and C. EnTtraman 1943 The production of cirrhosis in the liver of the normal dog by prolonged feeding of a high-fat diet. Am. J. Path., 19: 9-21.

Chatkoff, I. L., C. Entegnman, J. F. Ringhart and F. L. Retomirt 1943 Development of cirrhosis in the liver of dogs deprived of both pituitary and thyroid glands Proc. Soc. Biol. and Med., 54: 170-171.

CONNOR, C. L. 1938 Fatty infiltration of the liver and the development of cirrhosis in diabetes and chronic alcoholism. Am. J. Path., 14: 347-364.

Cowbry, E. V. 1943 Microscopic Technique in Biology and Medicine. Williams and Wilkins. Baltimore.

Davidson, J. N., AND C. WAymou'r 1944 The histochemical demonstration of ribonueleic acid in mammalian liver. Proc. Roy. Soc., Edinburgh, 68: (Sec. B) 96-98.

Dbane, H. W. 1946 The basophilic bodies in hepatie cells. Am. J. Anat., 78: $227-243$.

Dempsey, E. W., AND G. B. WIsLockI 1946 Histochemical contributions to physiology. Physiol. Rev., 26: 1-27.

Fteser, L. F. 1936 The Chemistry of the Natural Products Related to Phenanthrene. Reinhold Pub. Corp., New York.

FRY, E. G. 1937 The effect of adrenalectomy and thyroidectomy on ketonuria and liver fat content of the albino rat following injections of anterior pituitary extract. Endoer., 21 : 283-291.

Gersh, I., AND D. Bopian 1943 Histochemical analysis of changes in Rhesus motoneurons after root section. Biol. Symposia, 10: 163-184.

Gomori, G. 1939 Microtechnical demonstration of phosphatase in tissue sections. Proc. Soc. Exp. Biol. and Med., 42: 23-26.

1941a Distribution of acid phosphatase in the tissues under normal and under pathological conditions. Arch. Path., 32: 189-199.

1941b The distribution of phosphatase in normal organs and tissues.

J. Cell. and Comp. Physiol., $17:$ 71-83.

Gremstein, J. P. 1944 Nucleoproteins. Advanees in Protein Chemistry. Academic Press, Ine. New York. 
INatr, D. J. 1943 Relationship of the adrenal cortex to the metabolism of fat. J. Clin. Endocr., 3 : 603-612.

INGLE, D. J., C. H. LI AND H. M. Evans 1946 The effect of adrenocorticotropic hormone on the urinary excretion of sodium, chloride, potassium, nitrogen and glucose in normal rats. Endocr., $39: 39-42$.

INGLe, D. J., R. ShepPaRd, J. S. Evans AND M. H. KuIzenga 1945 A comparison of adrenal steroid diabetes and pancreatic diabetes in the rat. Endocr., 37 : 341-356.

INGLE, D. J., AND G. W. THORN 1941 A comparison of effects of 11-desoxycorticosterone acetate and 17-hydroxy-11-dehydrocorticosterone in partially depancreatized rats. Am. J. Physiol., 132: 670-678.

Jumian, O. C., D. E. Cluark, J. van Prohaska, C. Vhrmeulen and L. R. DragSTEIY 1942 The antagonistic effect of lipocaic and the anterior pituitary on fat metabolism. Am. J. Physiol., 138: 264-268.

KOHPF, G. F., H. W. HoRN, C. L. GEMMILL aNd G. W. ThORN 1941 The effect of adrenal cortical hormone on the synthesis of carbohydrate in liver slices. Am. J. Physiol., 135: 175-186.

Lmblond, C. P., N. Thoat and G. Segal 1939 Infiltration graisseuse du foie sous l'action des agents nocifs. Compt. rendu Soc. de Biol., 130: 1557-1559.

Li, C. H., H. M. Evans and M. E. Simpson 1943 Adrenocorticotropic hormone. J. Biol. Chem., 149 : 413-424.

Li, C. H., M. E. Simpson AND H. M. LvaNs 1942 Isolation of adrenocorticotropic hormone from sheep pituitaries. Science, 96: 450.

LIsoN, L. 1936 Histochemie Animale. Gauthier-Villars, Paris.

Long, C. N. H., B. KAtzin AND E. G. FRY 1940 .The adrenal cortex and carbohydrate metabolism. Endoer., $26: 309-344$.

LoNG, C. N. H., F. D. W. Lukmins AND E. G. FRY 1936 The effect of adrenalectomy and hypophysectomy upon the fatty infiltration of the liver following total panereatectomy in the eat. Am. J. Physiol., 116: 96.

MadKAY, E. M. 1937 Influence of adrenalectomy on liver fat as varied by diet and other factors. Am. J. Physiol., 120: 361-364.

MACKAY, E. M., AND R. H. BARNBS 1937 The effect of adrenalectomy on liver fat in fasting and after the administration of anterior pituitary extracts. Am. J. Physiol., 118: 525-527.

1938 Choline and pancreas extract on fatty livers and ketosis due to anterior pituitary extract. Proe. Soc. Exp. Biol. and Med., 38: 803-805.

MackAT, E. M., AND H. O. CARNE 1938 Influence of adrenalectomy and choline on the fat content of regenerating liver during fasting. Proc. Soc. Exp. Biol. and Med., 38: 131-133.

MAdDeN, S. C., ANd G. H. Whipple 1940 Plasma proteins: their source, production and utilization. Physiol. Rev., 20: 194-217.

Mchenry, E. W., AND J. M. Patrimson 1944 Lipotropic factors. Physiol. Rev., 24: 128-167.

MUKRnJ, B., AND R. C. GUHA 1938 The effect of anterior pituitary extraets and choline on the liver-fat of rabbits. Indian J. Med. Res, 26: 295-302. 
Pfuth, W. 1932 Die Leber. Handbuch der mikr. Anat. des Menschen 5: (part 2) 235. W. von Möllendorf, ed.

Reinecke, R. M., H. A. Ball and L. T. SAMukus 1939 High fat and high carbohydrate diets that can be fed to rats by stomach tube. Proc. Soc. Exp. Biol. and Med., 41: 44-46.

Sohulrz, A. 1924 Eine Methode des mikrochemischen Cholesterinnachweises am Gewebsschnitt. Centralbl. f. allg. Path., 35 : 314-316.

Secked, H. P. G. 1940 The influence of various physiological substances on the glycogenolysis of surviving rat liver. Endocr., 26: 97-101.

SELYE, H. 1939 Effect of muscular exercise on the fat content of the liver. Anat. Rec., 73 : 391-400.

1946 The general adaptation syndrome and the diseases of adaptation. J. Clin. Endoer., 6: 117-230.

VuRzAR, F., AND L. LASzT 1936 Nebennierenrinde und Fettwanderung. Biochem. Ztschr., 288: 356-358.

WACHSTEIN, M. 1945 Influence of dietary deficiencies and various poisons on the histochemical distribution of phosphatase in the liver. Arch. Path., $40: 57-67$.

ZWEM kR, R. L. 1933 A method for studying adrenal and other lipoids by a modified gelatin embedding and mounting technique. Anat. Rec., 5\%: 41-44. 


\section{PLATE 1}

EXPLANATION OF FIGURES

Figures 1-6 are of livers from rats of the same experimental group to show the extent of vacuolation in the hepatic cells (about $\times 200$ ). In figures 1-17 the central vein of the hepatic lobule is at the lower side and the portal canal at the upper side of the photograph. All adrenocorticotropin-treated animals whose livers are illustrated were given $8 \mathrm{mg}$ of the hormone daily for 10 days.

1 Rat 1204. Carbohydrate control. There is practically no visible vacuolation at this magnification. Large clumps of basophilic material are present in the cytoplasm. Zenker-acetic. $5 \mu$. Eosin and methylene blue.

2 Rat 1304. Carbohydrate, adrenocorticotropin. There is extensive vacuolation throughout the lobule being most pronounced in the middle and outer zones and with the largest vacuoles being located in the inner zone. Most of the cells are affected and the vacuoles of the midlle and outer zones are rather uniform in size. Technique as in figure 1.

3 Rat 604. Fat control. There is extensive vacuolation throughout the lobule but the vacuoles are of variable size and not as discrete as in figure 2. Technique as in figure 1.

4 Rat 504. Fat, adrenocorticotropin. There is probably more fat here than in its control (fig. 3) but the difference is not as great as between figures 1 and 2. Technique as in figure 1.

5 Rat 404. Protein control. There is practically no vacuolation visible. Bouin, $5 \mu$. Hematoxylin and eosin.

6 Rat 304. Protein, adrenocorticotropin. There is no significant ehange over the vacuolation as seen in the control. 'Technique as in figure 5 . 

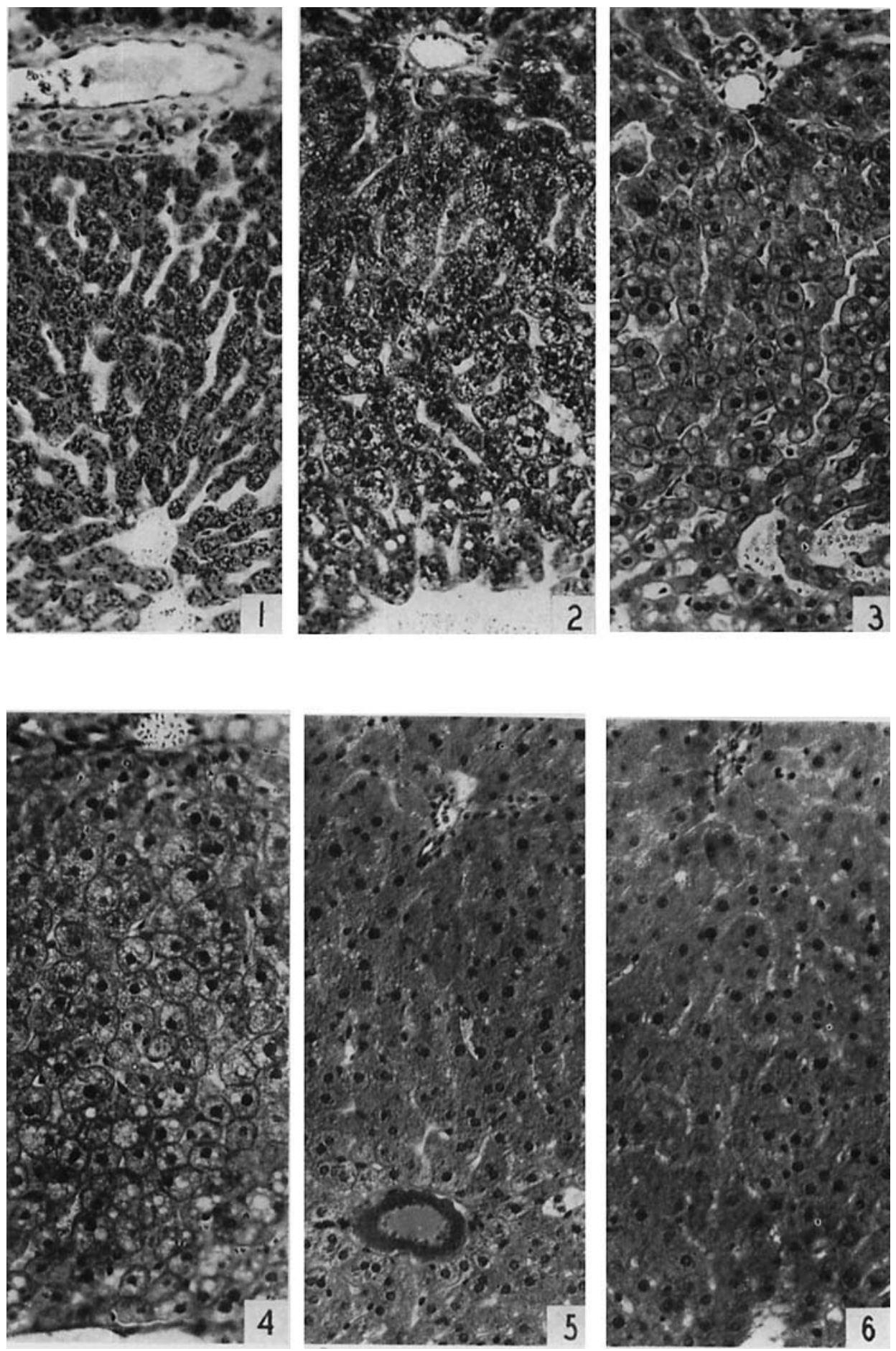


\section{PLATE 2}

\section{EXPLANATTON OF FIGURES}

The specimens for figures 7-12 were fixed in $10 \%$ neutral formalin, embedded in gelatin, sectioned at $15 \mu$ and stained with Harris' hematoxylin and Sudan IV. $\times 168$.

7 Rat 1204. Carbohydrate control. No fat is visible.

8 Rat 1404. Carbohydrate, adrenocorticotropin. A rather extensive accumulation of fat is present, being most marked in the middle and outer zones.

9 Rat 604. Fat control. Considerable fat is apparent, especially in the middle and outer zones.

10 Rat 504. Fat, adrenocorticotropin. There is much fat throughout the lobule but little change over the control (fig. 9).

11 Rat 404. Protein control. No fat is visible.

12 Rat 304. Protein, adrenocorticotropin. A very small amount of fat may be seen in a few cells. 

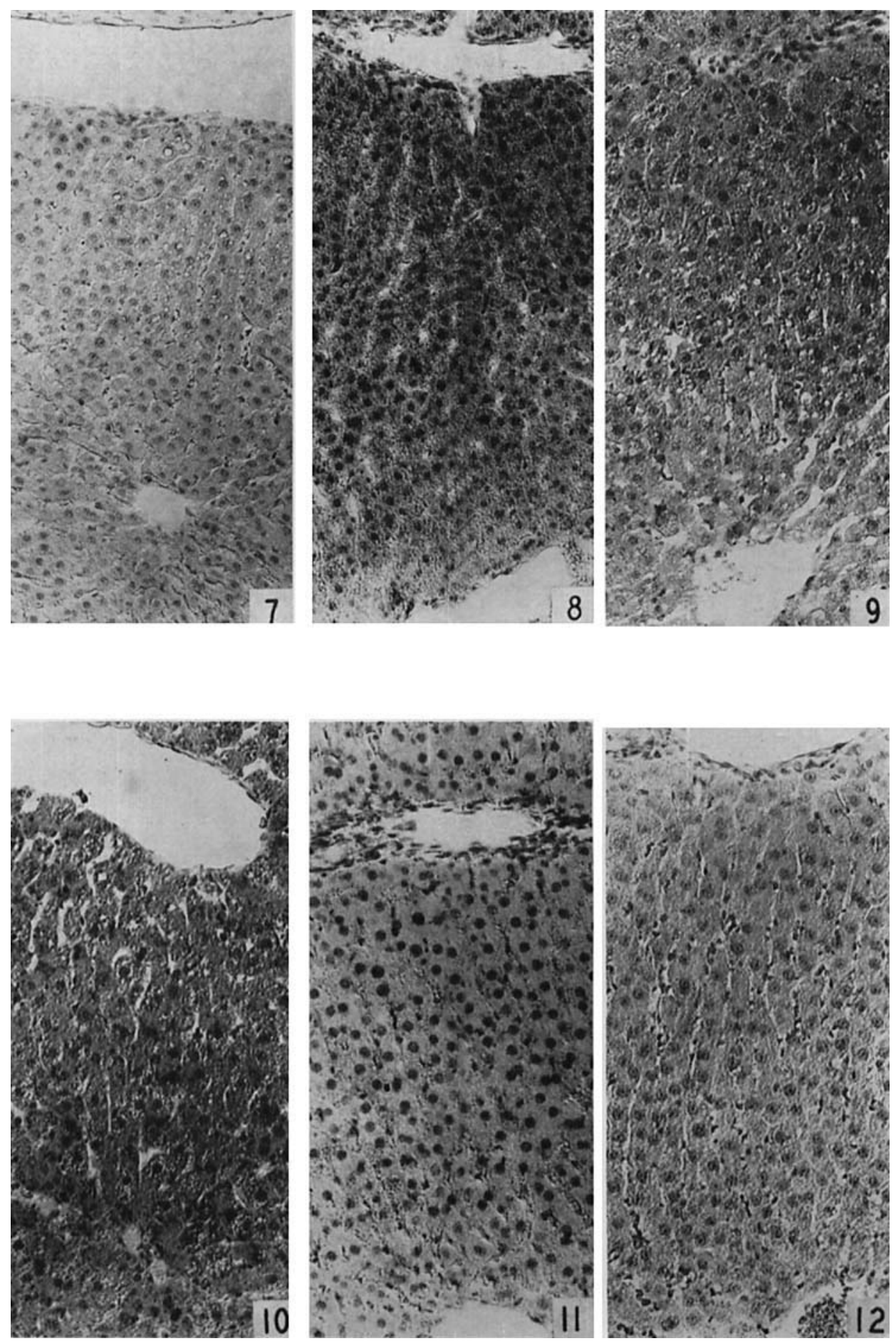


\section{P'LA'TE 3}

\section{FXPI,ANATION OY PIUURES}

13 Rut 1204. Carbohydrate control. An intense acid glycerophosphutase reaction is given by the nuclei and variably by the cytoplasm of the hepatic cells. Cold ucetone. Gomori acid phosphatase teelunique. Ineubntion at pH $5 . \times 180$.

14 Rat 1104. Carbohydrate, udrenocorticotropin. There is little change in the intensity of the renction, except that in this purticular lobule it is mure intense in the inner zone. Technique as in figure 13.

15 Rat 604. Fat control. Acid phosphatase is distributed generally tluroughout the lobule. Teelunique as in figure 13.

16 Rat 1404. Carbohydrate, sulrenocorticotropin. Alkuline glycerophosphatase is demonstruted in the nuelei, especially in the middle and outer zones and gives only a faint reaction in the cytoplasm. The capillaries near the bile duct of the portal canal aro intensely blakkened, $95 \%$ aleohol. Gomori alkulino phosphataso techinique. $\times 180$.

17 Rat 1204. Carboliydrate control. Stnining reaction similar to that illustrated in figure 16. Tochmigue as in figure 16.

18 Rat 1404. Carboligdrate, adrenocorticotropin. A small area of intense vacuolation surrounding a portal canal is shown. Such areas were rare and found only in rats treated with adrenocorticotropin on a high carbohydrate diet. Bouin. Ienatoxylin and eusin. $\times 128$. 

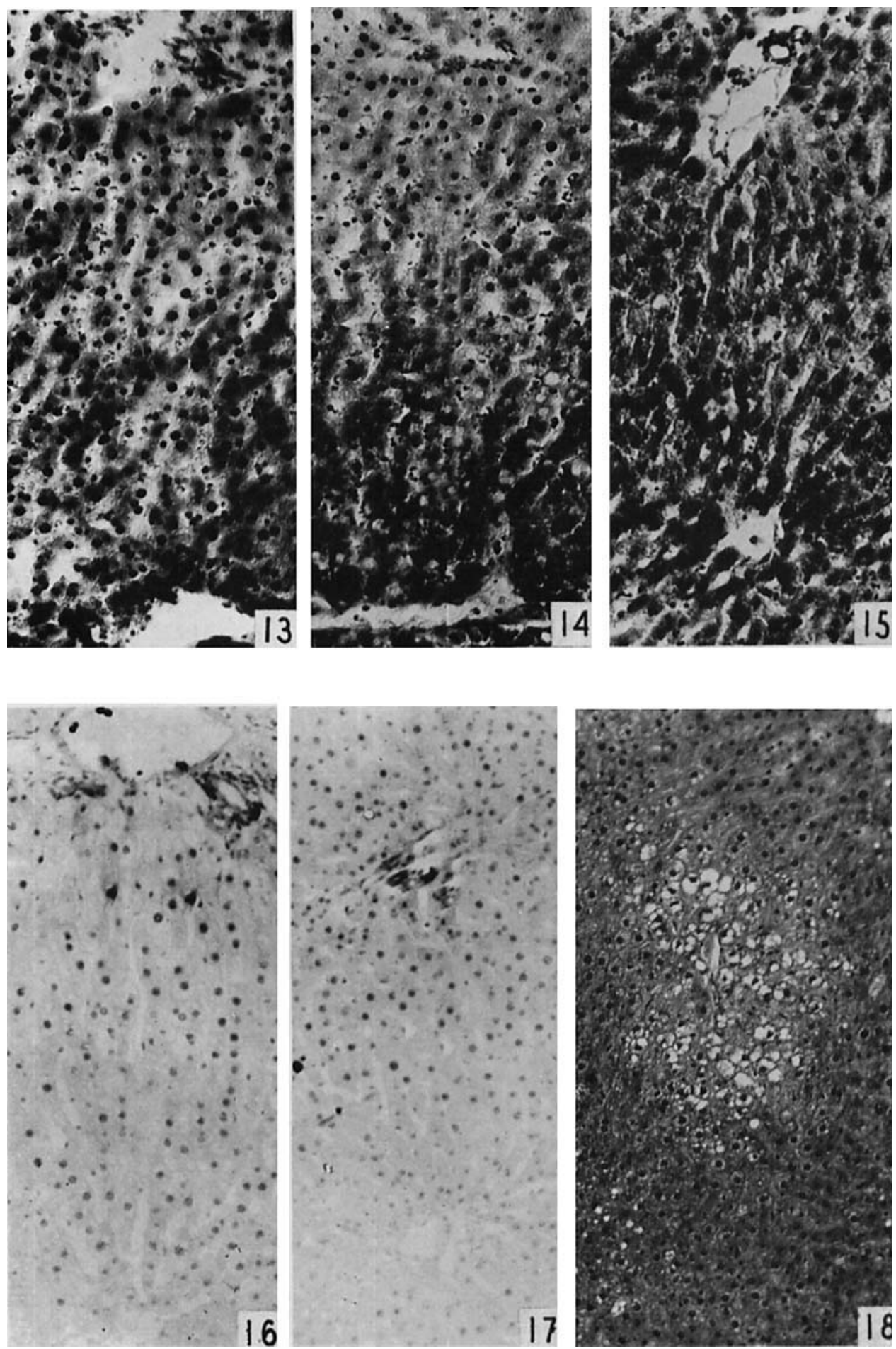
PLA'I'E 4

EXPLANA'I'ION OF FIGURES

In figures 19-23, the outlines of the cell and the nucleus were drawn with the aid of a camera lueida at a magnification of about 1100 from specimens fixed in Zenker-acetic, sectioned at $5 \mu$ and stained with eosin and methylene blue.

19 Rat 1204. Carbohydrate control. These cells are from the peripheral zone and illustrate the form and distribution of the basophilic material. It tended to be arranged in loose clumps and fibrillae. Diffuse, fine particles which stained less intensely with methylene blue may be found in the cytoplasm. Compare with figure 1.

20 Cells from the inner zone of the same lobule as those drawn in figure 19. 'The basophilic material is more densely clumped.

21 Rat 1304. Carbohydrate, adrenocorticotropin. These cells are from the peripheral zone of the lobule. The one at the right illustrates the vacuolation resulting chiefly from fatty infiltration which occurred in these animals with a concurrent reduction in basophilia. Most cells of the lobule were of this type and for their extent compare with figure 2.

22 These cells are from the inner zone close to the central vein of the same lobule as those drawn in figure 21. In this region there was less change from the control condition as illustrated in figure 20.

23 Rat 604. Fat control. The cells show the irregular vacuolation and general reduetion in basophilia which oeeurred on this dietary regimen without hormone treatment. Compare with figure 3.

24 Rat 1404. Carbohydrate, adrencorticotropin. This photograph shows the rather uniform size and distribution of the fat droplets within the liver cells, 10\% neutral formalin, $15 \mu$. Harris' hematoxylin and Sudan IV, $\times 432$. 

JUURTON L. BAKER AND OTHERS

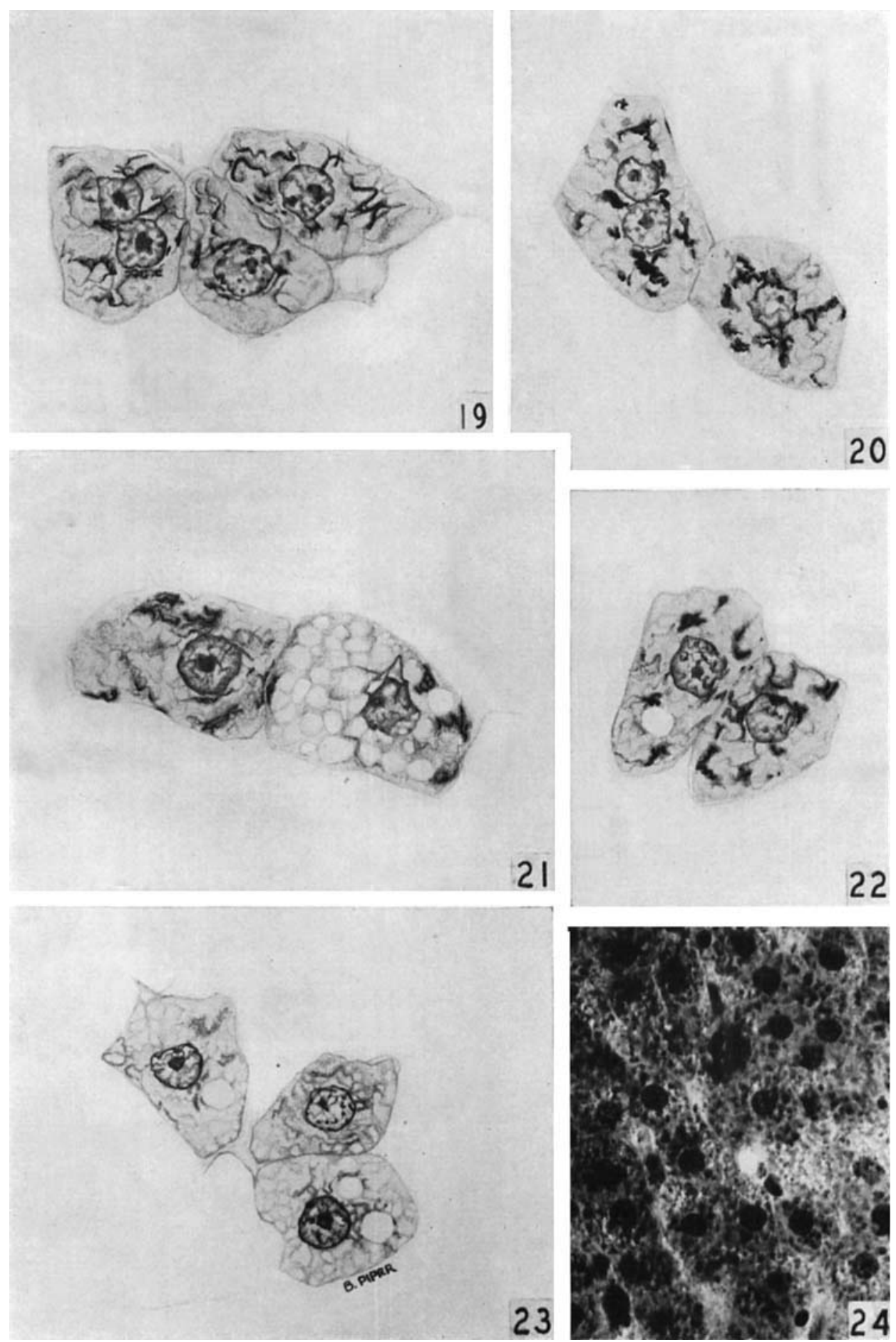

